\title{
Subjective wellbeing in the Indian general population: A validation study of the Personal Wellbeing Index
}

\begin{abstract}
Purpose:

The Personal Wellbeing Index (PWI) is a commonly used measure of life satisfaction that reflects a person's level of subjective wellbeing (SWB). The present study aimed to establish the validity and reliability of the PWI in a large sample of Indian adults and describe their SWB.
\end{abstract}

Methods:

2,004 Indian adults completed a cross-sectional online survey, which was presented in English and included the PWI and demographic questions. The sample was split to assess the psychometric properties of the 7-item $(n=$ 981) and 8 -item $(n=937)$ versions of the PWI.

Results:

Both the 7- and 8-item versions of the PWI demonstrated adequate internal consistency $(\alpha=. \underline{89}$ and .88

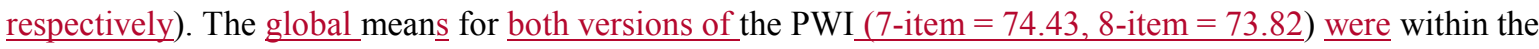
normative range for Western countries. Achieving in life had the lowest domain scores for both the 7-item $(M=$ 70.51) and 8-item $(M=68.37)$ versions; the spirituality or religion domain had the highest domain score in the $\underline{8 \text {-item version }(M=78.84)}$.

Conclusion:

The findings suggest that both the 7- and 8-item versions of the PWI are valid and reliable measures of life satisfaction for use in India. The global mean scores for both versions of the PWI were within the normative $\underline{\text { range for Western countries. In this study Indians reported high levels of satisfaction with their spirituality or }}$ religion, suggesting this domain may be an important contributor of SWB; however, more research is needed to determine this.

\section{Keywords}

Wellbeing, India, Life Satisfaction, Validation, Spirituality, Quality of Life 


\section{Subjective wellbeing in the Indian general population: A validation study of the Personal Wellbeing Index}

\section{Introduction}

There has been an increasing emphasis on measuring subjective wellbeing (SWB) at a national population level, alongside objective measures such as income and life expectancy [1,2]. Understanding SWB within a nation may help inform policy and resource allocation and identify sections of the population who may be at risk [3]. SWB refers to an individual's appraisal of their satisfaction with their life [3,4]. The Personal Wellbeing Index (PWI) is a commonly used domain-based scale that has been found to be a valid and reliable measure of SWB in a number of countries including: Australia, Canada, China, Columbia, Greece, Italy, and Spain $[3,5]$. The PWI measures seven domains that reflect the first-order deconstruction of the construct overall satisfaction with life [6]. These domains include satisfaction with: standard of living, personal health, achieving in life, personal relationships, personal safety, community-connectedness, and future security [5]. An eighth domain reflecting satisfaction with spirituality or religion is an optional item for inclusion if considered to be an important construct to a specific population sample [3].

An important finding with respect to SWB is that both individual and population means are highly stable [6]. The theory of SWB homeostasis suggests that this stability is because SWB is under genetically determined homeostatic control via processes that return it to a set point after fluctuations in environmental conditions [6,7]. Specifically, SWB is seen as being primarily comprised of an enduring, background mood state (happy, content, alert), and it is this mood state that is under homeostatic protection [7]. When the environment becomes adverse, several external and cognitive buffers may help to maintain homeostatically protected mood near the set point. These include money, personal relationships, and a sense of purpose or meaning in life $[1,8,7]$. Conversely, poverty, stress, poor relationships, lack of social support and lack of meaning in life may contribute to homeostatic failure when these are chronic and sufficiently severe $[6,8]$.

Because SWB is under homeostatic not environmental control, population means for SWB usually fall within a narrow range dubbed the normative range [9]. Cummins reported a normative range of 70-80 based on standardised scores from several Western countries, and subsequently found a broader range (60-80) based on analysis of studies from all geographic regions [10]. Consistent with the theory of SWB homeostasis, means for the PWI in Western countries fall between 70-80 [3]; while means for some non-Western countries such as China are typically around 10 points lower [10-12]. This may be due to cultural factors such as modesty, eschewal of extreme emotional expression, and not wanting to tempt fate, which may be more prevalent in collectivist cultures $[1,13,12,14]$.

India is a collectivist culture that may provide an interesting counterpoint to studies conducted in other non-Western cultures. There is some research reflecting the overall SWB of Indians at a national population level [15-17]. There is also a small body of literature that has explored SWB in India in relation to specific issues within the country such as: the caste system [18]; consumerism and conspicuous consumption [19,20]; food security [21]; homelessness [22,23]; and spirituality [24]. Another body of research in India has adopted a domain-based approach [25] and there is some evidence that domain-based scales may detect associations not found using single item measures [21]. One study [26] used the PWI in an Australian sample of 306 Sri Lankan and Indian first-generation migrant workers. Means for the PWI in this sample were slightly above the mean for Australia, and well above the means found in some other non-western countries (e.g. China, Hong Kong, Tibet, 
Thailand, and Algeria); migration is often undertaken as a means to increase wellbeing [26], which may help explain this result. The authors suggest that this work needs to be compared with research conducted in India or Sri Lanka, to determine if these means are consistent with the means in their country of birth. To date, no research has used the PWI in a large sample in India.

The PWI may be an appropriate tool for use in India as it demonstrates good validity and reliability in both Western and non-Western countries, and collectivist and individualistic cultures. In addition to providing a measure of overall SWB, the PWI also allows for more nuanced analysis at the level of life domains. One potentially important domain in the Indian context is satisfaction with spirituality or religion. This domain has not been found to make a unique contribution to the construct of SWB in all countries; for example, it was found to be relevant in Columbian and Algerian, but not Australian samples [3,27,28]. The spirituality or religion domain is an optional domain, and its use is deemed appropriate in samples where spiritual or religious beliefs are commonly held [3]. Wills [27] argues that in such contexts, spirituality contributes to satisfaction with life by being an "inner resource" that helps people feel that they are part of a deeper spiritual community and provides a sense of meaning and significance to life. India is a country in which spirituality and religion are an integral part of everyday life. The majority (88\%) of Indians consider themselves to be religious persons [16]; and participation in daily spiritual activities is linked to a sense of belonging [28], and higher satisfaction with life [24]. Therefore, the present study sought to determine the validity and reliability of the 7-item PWI, and the PWI with the optional spiritualty or religion domain in two separate samples of Indian adults.

Given the potential utility of the PWI in India, and the lack of evidence on norms and validity and reliability of the scale in large general population samples of Indian adults, the current research aims to determine the following:

1. Determine the reliability and validity of the 7-item PWI.

2. Determine the reliability and validity of the 8-item PWI, which includes the spirituality or religion item.

3. Describe the level of overall life satisfaction (SWB) and where PWI scores fall within the normative range for both versions of the index.

4. Describe the profile of the domains of satisfaction that contribute to overall life satisfaction.

5. Determine which demographic characteristics are related to global PWI scores.

\section{Methods}

\section{Sample characteristics and recruitment}

A total of 2,004 Indian adults (52.2\% male, $47.8 \%$ female) participated in an online survey. The respondents were recruited from a database of people who had expressed interest in participating in market research. Participants met criteria for participation in the study if they were 18 years or older, had been a resident of India for 5 years or more, and could read and understand English. Database members were emailed an invitation to participate that included a link to an online survey. Participants were presented with an information page that informed them that their survey responses would be collected anonymously. Consent was implied when participants continued with the survey after being presented with an information page. Ethical approval was obtained from Charles Sturt University Human Research Ethics Committee. 
Quota sampling was used to ensure that the sample had roughly equivalent numbers of males and females within each of six major regions (North; South; North-east; East; West; and Central). Once the quota was reached for each region, subsequent participants who attempted the survey were informed that the survey was now closed and thanked for their interest. There is no reason to consider that those who did not participate differed in any systematic way from those who did.

\section{Measures}

The online survey included the PWI and demographic items for age, gender, region, primary language spoken, household income, education level, and size of household; as well as other measures not discussed here that were part of a larger survey on food consumption habits in India. The PWI has been found to be a reliable (Cronbach alpha between .70 and .85) measure of overall SWB that has been validated in a range of populations [3]. The PWI consists of seven items reflecting satisfaction with specific life domains that are measured on an 11-point scale $(0=$ extremely dissatisfied to $10=$ extremely satisfied $)$. Higher scores reflect a higher level of satisfaction with each domain. The standardised population norm for Australia is 74.2 to 76.7 [29]; the norm is reported to be approximately 10 points lower for Asian populations [3]. An additional item measuring satisfaction with spiritualty or religion may be included if deemed appropriate for the specific population. The PWI manual [3] notes potential issues regarding the inclusion of both spirituality and religion in one question, in particular in contexts where people may have spiritual beliefs while not belonging to a formal religion. As India is a country in which the majority of people identify as being religious, and in the interests of parsimony, we retained the original double wording rather than including two questions.

India is a challenging country to research as there are broad regional cultural differences related to the large geographic size of the country and the number of different primary languages spoken. Adaptation of measurement scales is time consuming and costly, and often a barrier to researchers. The English version of the PWI was used, as English is a commonly used second language in India and it was a criteria of this study that participants could read and understand English. Two content experts — who were experienced in conducting research in India, and were born and lived in India with English as a second language - confirmed that the English version of the PWI had good face validity and was suitable for use in India.

\section{Data analysis}

Data were analysed using IBM SPSS Statistics version 24. The PWI manual recommends removal of data sets where the respondent consistently score at the top or the bottom of the range for all items as this suggests acquiescence or lack of understanding [3]; consequently, 83 participants were removed from the data set. The final data set included 1,918 participants (52.2\% male, $47.8 \%$ female), with a mean age of 39 . This sample was randomised into two samples to assess the psychometric properties of the 7-item PWI (Sample 1) and the 8-item PWI that included the item on spirituality and religion (Sample 2). Descriptive statistics were used to summarise the demographic and PWI items. Bivariate correlation analysis was used to identify relations between demographic variables and SWB, and inter-item correlations of the PWI. Cohen's [30] conventions were used to interpret the magnitude of the correlations. Standardised variables with scores ranging from 0 to 100 were created for each of the eight items on the PWI as described by The IWBG [3]. The PWI items were summed to create an overall PWI score. Exploratory factor analysis (EFA) was conducted to determine the factor structure of the 7-item and 8-item PWI using principle component analysis with varimax rotation, and Cronbach alpha was used to determine internal consistency. 


\section{Results}

\section{Demographic characteristics}

Sample 1. There were 981 participants (52.6\% male; 47.4\% female) in Sample 1. Most participants reported a graduate and above qualification (70.8\%); 47.5\% were employed full-time; and 38.1\% had a household annual income of between 500,000 to 999,999 Indian rupees (\$7,762 to \$15,524 USD), with 5.6\% earing under 30,000 rupees (\$465 USD).

Sample 2. There was a total of 937 (51.8\% male; 48.2\% female) participants in Sample 2. Similar to Sample 1 the majority of participants reported a graduate and above qualification $(61.42 \%) ; 48.6 \%$ were employed full-time; and 34.9\% had a household annual income of between 500,000 to 999,999 Indian rupees (\$7,762 to $\$ 15,524 \mathrm{USD})$, with 5.4\% earing under 30,000 rupees ( $\$ 465 \mathrm{USD})$. See Table 1 for a summary of demographic characteristics for both samples.

\section{Personal Wellbeing Index mean scores}

The global mean scores were $74.43(S D=17.15)$ for the 7 -item and $73.82(S D=16.36)$ for the 8 -item versions, which are within the normative range for Western countries [3] and just below the range for Australia [29]. Achieving in life had the lowest domain score in the 7-item and 8-item scale; $M=70.51(S D=22.52)$ and $M=68.37(S D=23.31)$ respectively. This is consistent with some other non-Western cultures (e.g., urban China) and with some Australian samples [12]. Interestingly, the spiritualty or religion domain had the highest domain score in the 8 -item version $(M=78.84, S D=21.04)$, which was higher than previously reported in Western cultures such as Australia [3] and in some non-Western cultures such as Thailand [31] and Algeria [28], but lower than that found in Columbia [27]. The means and summary statistics for the wellbeing domains in each version of the PWI are reported in Tables 2 and 3.

\section{Personal Wellbeing Index internal reliability}

The global measure of the PWI demonstrated excellent internal consistency in both the 7-item and 8item scale; $\alpha=.89$ and .88 respectively. The item-total statistics suggested that removal of any item would reduce this figure for either scale. The domain inter-item correlations were all significant $(p<.01)$ for both scales and ranged from moderate to substantial. Individual domain items had very strong significant $(p<.01)$ correlations with the global PWI score; between .76 and .79 for the 7-item scale, and between .66 and .76 for the 8-item scale. Although the association between the global PWI score and the spirituality or religion domain was lower than all other domains (ranging between .74 and .76) it remained large (.66). See Table 5.

\section{Personal Wellbeing Index validity}

Sample 1 (7-items). All statistical assumptions for an EFA were met. The skewness and kurtosis was acceptable for all items (see Table 2 and 3), and Bartlett's test of sphericity was significant $(p=.000)$ indicating that the item correlations were sufficient to proceed with an EFA [32]. As expected, one factor was found, which explained $60.7 \%$ of the variance; demonstrating the PWI to have good construct validity. As shown in Table 7, all factor loadings were greater than .50 indicating they have practical significance [32].

Sample 2 (8-items). All statistical assumptions were met, and the expected one factor solution was obtained, which explained less variance in the PWI construct (55.5\%) compared to the 7-item version. As shown in Table 6, the factor loadings indicate practical significance. While the loading for spirituality was acceptable (.66), it was lower than all other items (between .74 and .77). 


\section{Personal wellbeing and demographic characteristics}

Personal wellbeing was significantly positively correlated with age, time lived in India, level of education, and household income. This suggests that Indians who are older, better educated, with higher level of income have better SWB; however, the size of the associations were negligible to small. See Table 7 for correlation matrix.

\section{Discussion}

This is the first known study to determine the psychometric properties of the 7-item and 8-item PWI in two large samples of Indian adults. We found that both scales are valid and reliable measures of life satisfaction for use in India, which is consistent with previous research validating the use of the PWI in non-Western cultures $[33,12,13,31]$. Also consistent with previous studies we found one factor to reflect the construct of life satisfaction in both scales, explaining over $60 \%$ of the variance in the 7 -item scale, and over $55 \%$ in the 8 -item scale.

Interestingly, we found that both samples of Indian adults had a level of SWB that was within the normative range for Western cultures (70-80), and similar to that found in Australia [3]. Another study [26] that explored SWB in Indian and Sri Lankan first generation migrants in Australia found that the mean of the PWI for both cultural groups was marginally higher than that found in other Australian samples; 77.13 and 77.23 respectively. The authors suggest these findings may be explained by having better access to resources and services and lower rates of crime in Australia [26]. Means in the present study were somewhat lower (73.82 and 74.43), which may lend some support to this argument; this would need to be established in future research.

Much of the research using the PWI in non-Western countries has been conducted in countries such as China, where factors such as modesty may lead to an eschewal of responses at the extreme ends of the scale [13]. Such cultural response biases may in fact be limited to a specific set of countries, or even cultural groups within countries. For example, Webb [34] found higher levels of SWB in ethnic Tibetans compared to people in other areas of China, and argued that cultural factors such as modesty may be less important among ethnic Tibetans. Our results suggest that these cultural response biases may also play a less important role in India, including among the significant Hindu population. A study conducted with Malaysian Hindus and non-Hindus attending a religious festival supports this contention [8], finding a mean of 62.71 for non-Hindu attendees compared to 74.82 for the Hindu attendees. Our study adds to the literature on the cross-cultural validity of the PWI by showing that both the 7- and 8-item versions have factorial validity in India; however, caution is urged when comparing means between nations (due to factors such as cultural response bias) [7]. While research has investigated the cross-cultural equivalence of the scale between some countries [35], more research is needed to determine the scalar equivalence of the PWI in Western and non-Western samples (including India and China).

Another aim of our study was to describe the profile of SWB at the domain level. Mean scores ranged from 70.51 for achieving in life, to 77.65 for the how safe you feel domain in the 7-item PWI; and 68.37 for achieving in life, to 78.84 for spiritualty for the 8-item PWI. These scores suggest that Indians are relatively less satisfied with what they are achieving in life, compared to domains such as spirituality; personal safety; and being part of the community. This finding may reflect social structures and living conditions in India that may make achieving in life difficult for some Indians. 
Our findings also indicate that Indians have high levels of satisfaction with their spiritualty or religion. It is beyond the scope of this study to determine the independent contribution made by spirituality or religion to satisfaction with life as a whole; however, previous research indicates this domain may not make an important contribution to SWB. For example, although mean satisfaction with spirituality or religion was higher than other domains in a Muslim population [28], the contribution the domain made to satisfaction with life as a whole was very small $\left(R^{2}=.012\right.$ and .003 respectively). Similarly, the spirituality or religion domain did not make a unique contribution to satisfaction with life as a whole in first generation Indian migrants in Australia [26]. Although spirituality and religion are an important part of everyday life in India [36], more research is needed to determine whether they are best understood as a discrete domain of life satisfaction or as reflecting a set of external and cognitive buffers that help maintain homeostatically protected mood during difficult times [7]. In the Indian context, such buffers may include opportunities to engage in the wider community and gain access to social supports, a sense of purpose and meaning in life, and an emphasis on equipoise in the face of adverse environmental circumstances, described by the Sanskrit term Anasakti [24].

We also found that older people and those with a higher income had higher levels of SWB. Our findings on income are consistent with other research on SWB in India using alternative measures $[15,18]$, and can be expalined within the theory of SWB homeostasis. The theory suggests that money is one of several buffers against homeostatic defeat, enabling access to resources and services that facilitate maintenance of homeostatically protected mood in adverse environments [4]. Those on lower incomes (especially those living below or near the poverty line) may have less access to such resources, and may be more vulnerable to homeostatic defeat. The findings on age partially align with other research in India; for example, one Indian study found that younger men had lower Satisfaction with Life Scale scores than older men, while there was no difference for women [15]. In contrast, Fontaine and Yamada [18] used a single item measure asking participants to rate how happy they are, and found that younger people were happier than older people. It may be that, with respect to age, satisfaction with life may refer to aspects of life that are not well measured by the term happiness. While significant, the associations found in our study are very small and caution should be used when interpreting these results.

\section{Limitations}

This study is the first to measure the SWB of adults in a large sample of Indian adults using the PWI; however, there are limitations that need consideration. First, there is some evidence that online panel recruitment (used in this study) may yield samples that over-represent people with low SWB [37]. In our study, means for the PWI were within the normative range for Western countries [3], suggesting that the samples were adequately represented in relation to their level of SWB; however, more research is needed with alternative recruitment strategies to address this issue. Second, the sampling strategy limited the opportunity for many people of a low socioeconomic status to access the study, as they needed access to the Internet and English language proficiency. Therefore, this sample is likely to reflect a segment of the Indian population who is well educated and have a relatively high standard of living; consequently, the results cannot be generalised to all Indians. More research is needed to determine the SWB of the broader Indian population. This is particularly important as poverty is a significant issue in India. In our sample, 5,5\% had an income below the poverty line, which is considerably lower than the $21 \%$ estimated by the World Bank in 2017 [38]. Such individuals have significant life challenges that are likely to impact on their quality of life and contribute to homeostatic defeat. 
Third, India is a highly diverse country with respect to social organisation. The present study did not address caste or religion as potential factors influencing wellbeing; although, these have been shown to be relevant to SWB in general in India $[25,17,18]$. Further research could determine relations between the PWI domains and caste membership and religious affiliation.

Our survey was unable to explore if the spiritualty or religion domain contributed any unique variance to overall satisfaction with life as the item measuring global satisfaction with life was not included in our survey. However, we used robust a-priori theoretical reasoning to include the spiritualty or religion item, as discussed in the Methods section, The factor loading in our study was acceptable (.66); however, it was smaller than loadings for all other items, suggesting that it may differ in some important respect. Consistent with the vast majority of research on the PWI we based our analysis on classical test theory. Rasch analysis may provide further insights into the psychometric properties of the PWI in India with respect to the spiritualty or religion domain. An additional limitation with respect to this item is potential ambiguity due to the double wording (spirituality or religion). Individuals who consider themselves to be spiritual but not religious may have problems with this question [3]. We opted to include the single item reflecting satisfaction with spirituality or religion because India is a country in which a large majority of people describe themselves as religious [16]. Future research could include two separate items reflecting spirituality and religion [39].

\section{Conclusion}

This is the first known study to describe the level of overall life satisfaction (SWB) in a large sample of Indian adults using the PWI, and to demonstrate the internal consistency and factorial validity of the 7-item and 8-item PWI in this population. Our study found that global PWI mean scores are similar to those of Western countries such as Australia. Satisfaction with spirituality and religion was found to have the highest mean of the eight measured domains, while achieving in life had the lowest.

\section{Acknowledgements}

We would like to thank the people who participated in the study.

\section{Compliance with Ethical Standards}

Conflict of Interest: All authors declare that they have no conflict of interest.

Ethical approval: This study was conducted in accordance with the ethical standards of Charles Sturt University research ethics committee and with the 1964 Helsinki declaration and its later amendments.

Informed consent: Informed consent was obtained from all individual participants included in the study. 


\section{References}

1. Cummins, R. A. (2007). Social indicators and social development. Paper presented at the Global Business and Technology Association Tenth International Conference, New York, NY,

2. Diener, E., \& Tay, L. (2015). Subjective well-being and human welfare around the world as reflected in the Gallup World Poll. International Journal of Psychology, 50(2), 135-149, doi:10.1002/ijop.12136.

3. The International Wellbeing Group (2013). Personal Wellbeing Index - Adult (PWI-A).

4. Cummins, R. A. (2018). The golden triangle of happiness: Essential resources for a happy family. International Journal of Child, Youth and Family Studies, 9(4), 12-39, doi:10.18357/ijcyfs94201818638.

5. Misajon, R. A., Pallant, J., \& Bliuc, A.-M. (2016). Rasch analysis of the Personal Wellbeing Index. Quality of Life Research, 25(10), 2565-2569, doi:10.1007/s11136-016-1302-x.

6. Cummins, R. A. (2010). Subjective wellbeing, homeostatically protected mood and depression: A synthesis. Journal of Happiness Studies, 11(1), 1-17, doi:10.1007/s10902-009-9167-0.

7. Cummins, R. A. (2019). Wellbeing Across Cultures: Issues of Measurement and the Interpretation of Data. In K. D. Keith (Ed.), Cross-Cultural Psychology: Contemporary Themes and Perspectives (Second Edition ed.): John Wiley \& Sons Ltd.

8. Mellor, D., Hapidzal, F. M., Teh, K., Ganesan, R., Yeow, J., Latif, R. A., et al. (2012). Strong spiritual engagement and subjective well-being: A naturalistic investigation of the Thaipusam festival. Journal of Spirituality in Mental Health, 14(3), 209-225, doi:10.1080/19349637.2012.697375.

9. Cummins, R. A. (1995). On the trail of the gold standard for subjective well-being. Social Indicators Research, 35(2), 179-200, doi:10.1007/BF01079026.

10. Cummins, R. A. (1998). The second approximation to an international standard for life satisfaction. Social Indicators Research, 43(3), 307-334, doi:10.1023/A:1006831107052.

11. Chen, Z., \& Davey, G. (2008). Normative life satisfaction in Chinese societies. Social Indicators Research, 89(3), 557-564, doi:10.1007/s11205-008-9250-7.

12. Lau, A. L. D., Cummins, R. A., \& McPherson, W. (2005). An investigation into the cross-cultural equivalence of the Personal Wellbeing Index. Social Indicator Research, 72, 403-430.

13. Lai, L. C. H., Cummins, R. A., \& Lau, A. L. D. (2013). Cross-cultural difference in subjective wellbeing: Cultural response bias as an explanation. Social Indicators Research, 114(2), 607-619, doi:10.1007/s11205-012-0164-z.

14. Rözer, J., \& Kraaykamp, G. (2012). Income inequality and subjective well-being: A cross-national study on the conditional effects of individual and national characteristics. Social Indicators Research, 113(3), 1009-1023, doi:10.1007/s11205-012-0124-7.

15. Agrawal, J., Murthy, P., Philip, M., Mehrotra, S., Thennarasu, K., John, J. P., et al. (2011). Sociodemographic correlates of subjective well-being in urban India. Social Indicators Research, 101(3), 419-434, doi:10.1007/s11205-010-9669-5.

16. Inglehart, R., Haerpfer, C., Moreno, A., Welzel, C., Kizilova, K., Diez-Medrano, J., et al. (2014). World Values Survey: Round Six - Country-Pooled Datafile Madrid: JD Systems Institute. 
17. White, S. C., Gaines Jr., S. O., \& Jha, S. (2014). Inner wellbeing: Concept and validation of a new approach to subjective perceptions of wellbeing - India. Social Indicators Research, 119(2), 723-746, doi:DOI 10.1007/s11205-013-0504-7.

18. Fontaine, X., \& Yamada, K. (2014). Caste comparisons in India: Evidence from subjective well-being data. World Development, 64, 407-419, doi:10.1016/j.worlddev.2014.06.025.

19. Dittmar, H., \& Kapur, P. (2011). Consumerism and well-being in India and the UK: Identity projection and emotion regulation as underlying psychological processes. Psychological Studies, 56(1), 71-85, doi:10.1007/s12646-011-0065-2.

20. Linssen, R., van Kempen, L., \& Kraaykamp, G. (2011). Subjective well-being in rural India: The curse of conspicuous consumption. Soc Indic Res, 101(1), 57-72, doi:10.1007/s11205-010-9635-2.

21. White, S. C., Fernandez, A., \& Jha, S. (2016). Beyond the grumpy rich man and the happy peasant: mixed methods and the impact of food security on subjective dimensions of wellbeing in India. Oxford Development Studies, 44(3), 332-348, doi:10.1080/13600818.2015.1120278.

22. Biswas-Diener, R., \& Diener, E. (2006). The subjective well-being of the homeless, and lessons for happiness. Social Indicators Research, 76(2), 185-205, doi:10.1007/s11205-005-8671-9.

23. Biswas-Diener, R., \& Diener, E. (2001). Making the best of a bad situation: Satisfaction in the slums of Calcutta. Social Indicators Research, 55(3), 329-352, doi:10.1023/A:1010905029386.

24. Banth, S., \& Talwar, C. (2012). Anasakti, the Hindu ideal, and its relationship to well-being and orientations to happiness. [journal article]. Journal of Religion and Health, 51(3), 934-946, doi:10.1007/s10943010-9402-3.

25. Fernandez, A., White, S. C., \& Jha, S. (2014). Wellbeing Pathways Report: India Round 2. UK: University of Bath.

26. Gunasekara, A., Rajendran, D., \& Grant, S. (2014). Life satisfaction of Sri Lankan and Indian skilled migrants in Australia. Asian and Pacific Migration Journal, 23(4), 475-499, doi:10.1177/011719681402300408.

27. Wills, E. (2009). Spirituality and subjective well-being: Evidences for a new domain in the Personal WellBeing Index. Journal of Happiness Studies, 10(1), 49-69, doi:10.1007/s10902-007-9061-6.

28. Tiliouine, H. (2009). Measuring satisfaction with religiosity and its contribution to the Personal Well-Being Index in a Muslim sample. Applied Research Quality Life, 4, 91-108, doi:10.1007/s11482-009-9074-x.

29. Capic, T., Fuller-Tyszkiewicz, M., Cummins, R. A., Khor, S., Richardson, B., Greenwood, C., et al. (2018). Australian Unity Wellbeing Index: : Report 35.0, Financial Control. Geelong: Australian Centre on Quality of Life, School of Psychology, Deakin University.

30. Cohen, J. (1992). A power primer. Psychological Bulletin, 112(1), 155-159.

31. Yiengprugsawan, V., Seubsman, S., Khamman, S., Lim, L. L. Y., Sleigh, A. C., \& the Thai Cohort Study Team (2010). Personal Wellbeing Index in a national cohort of 87,134 Thai adults. Social Indicators Research, 98(2), 201-215, doi:10.1007/s11205-009-9542-6.

32. Hair, J. F., Black, W. C., Babin, B. J., \& Anderson, R. E. (Eds.). (2014). Multivariate Data Analysis (7th ed.). Delhi, India: Pearson.

33. Smyth, R., Nielsen, I., \& Zhai, Q. (2009). Personal well-being in urban China. Social Indicators Research, 95(2), 231-251, doi:10.1007/s11205-009-9457-2. 
34. Webb, D. (2008). Subjective wellbeing on the Tibetan Plateau: An exploratory investigation. Journal of Happiness Studies, 10(6), 753-768, doi:10.1007/s10902-008-9120-7.

35. Jovanović, V., Cummins, R. A., Weinberg, M., Kaliterna, L., \& Prizmic-Larsen, Z. (2019). Personal Wellbeing Index: A cross-cultural measurement invariance study across four countries. Journal of Happiness Studies, 20, 759-775, doi:10.1007/s10902-018-9966-2.

36. Kumar, N., \& Misra, G. (2016). Impact of daily spiritual experiences and private religious practices on social well-being amoung different religious community. Indian Journal of Positive Psychology, 7(3), 318-324.

37. Weinberg, M. K., Cummins, R. A., Webb, D. A., \& Gwozdz, W. (2018). Incentivised online panel recruitment and subjective wellbeing: Caveat emptor. Journal of Well-Being Assessment, 2(1), 41-55, doi:10.1007/s41543-018-0010-4.

38. World Bank (2017). Country Poverty Brief: India. USA: World Bank.

39. Castellá Sarriera, J., Casasb, F., Alfaroc, J., Bedina, L. v., Wachholz Strelhowa, M. R., Absa, D., et al. (2014). Psychometric properties of the Personal Wellbeing Index in Brazilian and Chilean adolescents including spirituality and religion. doi:10.1590/1678-7153.201427411. 
Table 1.

Summary of descriptive statistics for demographic characteristics of Sample 1 and Sample 2.

\begin{tabular}{|c|c|c|c|c|c|c|c|c|c|}
\hline \multirow[t]{2}{*}{ Variable } & \multicolumn{2}{|c|}{$\begin{array}{l}\text { Sample } 1 \\
\mathrm{n}=981\end{array}$} & \multicolumn{2}{|c|}{$\begin{array}{c}\text { Sample } 2 \\
n=937\end{array}$} & \multirow[t]{2}{*}{ Variable } & \multicolumn{2}{|c|}{$\begin{array}{l}\text { Sample } 1 \\
\mathrm{n}=981\end{array}$} & \multicolumn{2}{|c|}{$\begin{array}{l}\text { Sample } 2 \\
\mathrm{n}=937\end{array}$} \\
\hline & $\mathrm{n}$ & $\%$ & $\mathrm{n}$ & $\%$ & & $\mathrm{n}$ & $\%$ & $\mathrm{n}$ & $\%$ \\
\hline Age & & & & & Highest level of education & & & & \\
\hline $18-25$ & 221 & 22.5 & 211 & 22.5 & Primary & 2 & 0.2 & 1 & 0.1 \\
\hline $26-35$ & 232 & 23.6 & 218 & 23.3 & Middle & 2 & 0.2 & 1 & 0.1 \\
\hline $36-45$ & 194 & 19.8 & 184 & 19.5 & Matric/Secondary & 17 & 1.7 & 16 & 1.7 \\
\hline $46-55$ & 157 & 16.0 & 151 & 16.1 & Higher secondary & 84 & 8.6 & 88 & 9.4 \\
\hline $56-65$ & 149 & 15.2 & 148 & 15.8 & Non-technical diploma & 54 & 5.5 & 71 & 7.5 \\
\hline Over 65 & 28 & 2.9 & 25 & 2.7 & Technical diploma & 113 & 11.5 & 165 & 17.6 \\
\hline $\begin{array}{l}\text { How long lived } \\
\text { in India }\end{array}$ & & & & & Graduate $\&$ above & 695 & 70.8 & 575 & 61.4 \\
\hline $5-10$ years & 2 & 0.2 & 4 & 0.4 & Other & 14 & 1.4 & 20 & 2.1 \\
\hline $11-20$ years & 19 & 1.9 & 10 & 1.1 & Employment status & & & & \\
\hline $31-35$ years & 5.7 & 5.8 & 31 & 3.3 & Employed full-time & 467 & 47.6 & 455 & 48.6 \\
\hline $36-50$ years & 57 & 5.8 & 45 & 4.8 & Employed part-time & 65 & 6.6 & 71 & 7.6 \\
\hline $\begin{array}{l}\text { More than } \\
50 \text { years }\end{array}$ & 42 & 4.3 & 31 & 3.3 & Self-employed & 150 & 15.3 & 95 & 10.1 \\
\hline All my life & 804 & 82.0 & 816 & 87.1 & $\begin{array}{l}\text { Homemaker } \\
\text { (housewife/husband) }\end{array}$ & 131 & 13.4 & 134 & 14.3 \\
\hline Region & & & & & Retired & 22 & 2.2 & 20 & 2.1 \\
\hline South & 196 & 20.0 & 187 & 20.0 & Student & 102 & 10.4 & 102 & 10.9 \\
\hline North East & 39 & 4.0 & 43 & 4.5 & Unemployed & 44 & 4.5 & 60 & 6.4 \\
\hline North & 243 & 24.8 & 234 & 25.0 & Household income & & & & \\
\hline Central & 82 & 8.4 & 77 & 8.2 & Under 30,000 & 55 & 5.6 & 51 & 5.4 \\
\hline Western & 201 & 20.5 & 188 & 20.1 & 30,000 to 99,999 & 83 & 7.4 & 71 & 7.6 \\
\hline Eastern & 220 & 22.4 & 208 & 22.2 & 100,000 to 199,999 & 65 & 6.6 & 63 & 6.7 \\
\hline Size of family & & & & & 200,000 to 499,999 & 259 & 26.4 & 277 & 29.6 \\
\hline 1 or 2 people & 74 & 7.5 & 55 & 5.9 & 500,000 to 999,999 & 374 & 38.1 & 327 & 34.9 \\
\hline 3 or 4 people & 498 & 50.8 & 481 & 51.3 & $1,000,000$ or more & 155 & 15.8 & 148 & 15.8 \\
\hline $\begin{array}{l}5 \text { or more } \\
\text { people }\end{array}$ & 409 & 41.7 & 401 & 42.8 & & & & & \\
\hline
\end{tabular}

Note. Sample 1 was used to examine the 7 -item version of the PWI and Sample 2 to examine the 8 -item version. 
Table 2.

Sample 1 mean, standard deviation, standard error, difference from PWI score, kurtosis, and skewness for each of the PWI domains

\begin{tabular}{|c|c|c|c|c|c|c|}
\hline PWI domain & $M$ & $S E$ & $S D$ & Diff & Skewness & Kurtosis \\
\hline Achieving in life & 70.51 & 0.72 & 22.52 & -3.92 & -0.86 & 0.47 \\
\hline Future security & 73.83 & 0.71 & 22.30 & -0.6 & -1.12 & 1.22 \\
\hline Standard of living & 74.66 & 0.72 & 22.44 & 0.23 & -1.08 & 1.01 \\
\hline Health & 74.14 & 0.68 & 21.30 & -0.29 & -1.05 & 1.11 \\
\hline Personal relationships & 74.15 & 0.77 & 24.13 & -0.28 & -1.10 & 0.84 \\
\hline Part of your community & 76.13 & 0.68 & 21.31 & 1.7 & -1.25 & 1.77 \\
\hline How safe you feel & 77.65 & 0.64 & 20.08 & 3.22 & -1.10 & 1.30 \\
\hline Personal Wellbeing Index (global) & 74.43 & 0.55 & 17.15 & & -1.12 & 1.22 \\
\hline
\end{tabular}

Note. $M=$ mean, $S D=$ standard deviation, $S E=$ standard error. 
Table 3.

Sample 2 mean, standard deviation, standard error, difference from PWI score, kurtosis, and skewness for each of the PWI domains

\begin{tabular}{lcccccc}
\hline PWI domain & $M$ & $S E$ & $S D$ & Diff & Skewness & Kurtosis \\
\hline Achieving in life & 68.37 & 0.76 & 23.31 & -4.45 & -0.79 & 0.32 \\
Future security & 72.72 & 0.74 & 22.84 & -1.10 & -0.95 & 0.64 \\
Standard of living & 71.99 & 0.74 & 22.82 & -1.83 & -0.89 & 0.58 \\
Health & 73.50 & 0.67 & 20.51 & -0.32 & -0.91 & 0.74 \\
Personal relationships & 73.56 & 0.78 & 24.04 & -0.26 & -0.98 & 0.50 \\
Part of your community & 75.45 & 0.68 & 20.95 & 1.63 & -1.02 & 1.13 \\
How safe you feel & 76.16 & 0.66 & 20.32 & 2.34 & -0.86 & 0.47 \\
Spirituality or religion & 78.84 & 0.69 & 21.04 & 5.02 & -1.30 & 1.80 \\
Personal Wellbeing Index (global) & 73.82 & 0.53 & 16.36 & & -0.87 & 0.80 \\
\hline
\end{tabular}

Note. $M=$ mean, $S D=$ standard deviation, $S E=$ standard error. 
Table 4

Sample 1 inter-item (domain) correlations of the PWI.

\begin{tabular}{|c|c|c|c|c|c|c|c|c|}
\hline & $\begin{array}{l}\text { Personal } \\
\text { Wellbeing }\end{array}$ & $\begin{array}{l}\text { Standard of } \\
\text { living }\end{array}$ & Health & $\begin{array}{l}\text { Achieving } \\
\text { in life }\end{array}$ & $\begin{array}{l}\text { Personal } \\
\text { relationships }\end{array}$ & $\begin{array}{l}\text { Safe you } \\
\text { feel }\end{array}$ & $\begin{array}{l}\text { Part of your } \\
\text { community }\end{array}$ & $\begin{array}{l}\text { Future } \\
\text { security }\end{array}$ \\
\hline Personal Wellbeing & 1 & & & & & & & \\
\hline Standard of living & $.78 * *$ & 1 & & & & & & \\
\hline Health & $.78^{* *}$ & $.63 * *$ & 1 & & & & & \\
\hline Achieving in life & $.79 * *$ & $.61 * *$ & $.58 *$ & 1 & & & & \\
\hline Personal relationships & $.78^{* *}$ & $.52 * *$ & $.55^{* *}$ & $.55^{* *}$ & 1 & & & \\
\hline Safe you feel & $.77^{* *}$ & $.51^{* *}$ & $.51^{* *}$ & $.51^{* *}$ & $.51 * *$ & 1 & & \\
\hline $\begin{array}{l}\text { Part of your } \\
\text { community }\end{array}$ & $.76^{* *}$ & $.45^{* *}$ & $.49^{* *}$ & $.49^{* *}$ & $.54 * *$ & $.61 * *$ & 1 & \\
\hline Future security & $.79 * *$ & $.54 * *$ & $.51^{* *}$ & $.56^{* *}$ & $.53 * *$ & $.59 * *$ & $.57 * *$ & 1 \\
\hline
\end{tabular}

$* * p<0.01$ 
Table 5.

Sample 2 inter-item (domain) correlations of the PWI.

\begin{tabular}{|c|c|c|c|c|c|c|c|c|c|}
\hline & $\begin{array}{l}\text { Personal } \\
\text { Wellbeing }\end{array}$ & $\begin{array}{l}\text { Standard of } \\
\text { living }\end{array}$ & Health & $\begin{array}{l}\text { Achieving } \\
\text { in life }\end{array}$ & $\begin{array}{l}\text { Personal } \\
\text { relationships }\end{array}$ & $\begin{array}{l}\text { Safe you } \\
\text { feel }\end{array}$ & $\begin{array}{l}\text { Part of your } \\
\text { community }\end{array}$ & $\begin{array}{l}\text { Future } \\
\text { security }\end{array}$ & $\begin{array}{l}\text { Spirituality } \\
\text { or religion }\end{array}$ \\
\hline Personal Wellbeing & 1 & & & & & & & & \\
\hline Standard of living & $.76^{* *}$ & 1 & & & & & & & \\
\hline Health & $.76^{* *}$ & $.59^{* *}$ & 1 & & & & & & \\
\hline Achieving in life & $.76^{* *}$ & $.58 * *$ & $.51^{* *}$ & 1 & & & & & \\
\hline Personal relationships & $.75^{* *}$ & $.49 * *$ & $.52 * *$ & $.47 * *$ & 1 & & & & \\
\hline Safe you feel & $.74 * *$ & $.47 * *$ & $.57 * *$ & $.46^{* *}$ & $.44 * *$ & 1 & & & \\
\hline $\begin{array}{l}\text { Part of your } \\
\text { community }\end{array}$ & $.76^{* *}$ & $.51 * *$ & $.45^{* *}$ & $.50^{* *}$ & $.56^{* *}$ & $.53 * *$ & 1 & & \\
\hline Future security & $.76^{* *}$ & $.50 * *$ & $.50^{* *}$ & $.57^{* *}$ & $.53 * *$ & $.50 * *$ & $.49^{* *}$ & 1 & \\
\hline Spirituality or religion & $.66^{* *}$ & $.38 * *$ & $.40^{* *}$ & $.37 * *$ & $.40 * *$ & $.49 * *$ & $.52 * *$ & $.41^{* *}$ & 1 \\
\hline
\end{tabular}

$* * p<0.01$ 
Table 6.

Factor loadings for the PWI for Sample 1 (7-items) and Sample 2 (8-items)

\begin{tabular}{lll}
\hline Item & $\begin{array}{l}\text { Factor loading } \\
\text { Sample 1 }\end{array}$ & $\begin{array}{l}\text { Factor loading } \\
\text { Sample 2 }\end{array}$ \\
\hline Future security & .79 & .76 \\
Part of your community & .76 & .77 \\
Health & .79 & .76 \\
Standard of living & .78 & .76 \\
Safe you feel & .78 & .75 \\
Achieving in life & .79 & .76 \\
Personal relationships & .77 & .74 \\
Spirituality or religion & & .66 \\
\hline
\end{tabular}


Table 7.

Correlations between SWB and demographic variables for Sample 1 and Sample 2

\begin{tabular}{|c|c|c|c|c|c|c|}
\hline & Gender & Age & $\begin{array}{l}\text { Time lived } \\
\text { in India }\end{array}$ & $\begin{array}{l}\text { Level of } \\
\text { education }\end{array}$ & $\begin{array}{l}\text { Household } \\
\text { income }\end{array}$ & $\begin{array}{l}\text { Size of } \\
\text { family }\end{array}$ \\
\hline \multicolumn{7}{|l|}{ Sample 1} \\
\hline SWB & .01 & $.07 * *$ & $.07 *$ & $.14^{* *}$ & $.20 * *$ & .02 \\
\hline \multicolumn{7}{|l|}{ Sample 2} \\
\hline SWB & $.11^{* *}$ & $.14^{* *}$ & $.09 * *$ & $.15^{* *}$ & $.20 * *$ & .00 \\
\hline
\end{tabular}

$* p<.05, * * p<.01$

Note. SWB $=$ total summed scores of the 7-item PWI (Sample 1) and 8-item PWI (Sample 2). 